\title{
Responsabilidade Social Corporativa: uma Investigação Sobre a Percepção do Consumidor
}

\author{
Daniela Abrantes Ferreira Serpa \\ Lucelena Ferreira Fourneau
}

\section{RESUMO}

No contexto brasileiro, observa-se crescente interesse das empresas quanto a assumir postura de responsabilidade social corporativa. Neste sentido, o entendimento do comportamento do consumidor, desde o que pensa sobre o assunto até que influência este exerce sobre suas decisões de compra, é de grande valia para decisões estratégicas de marketing. O objetivo deste estudo, de caráter exploratório, é ampliar o nível de conhecimento a respeito das reações de consumidores brasileiros à postura de responsabilidade social das empresas. Foi realizada uma pesquisa qualitativa, cujo método escolhido foi a entrevista semi-estruturada, visando a aprofundamento do tema junto a cada consumidor pesquisado. Os resultados encontrados apontam uma visão estreita da responsabilidade social corporativa, priorizando um ou dois aspectos na tentativa de definição do termo. Os aspectos mencionados se referem principalmente à resolução de problemas básicos do país, tais como saúde e educação, e a obrigações legais da empresa, como falar a verdade para seus consumidores. No que se refere à influência deste tema nas decisões de compra, os resultados apontam uma maior importância da informação negativa a respeito da atitude da empresa perante a sociedade.

Palavras-chave: responsabilidade social; comportamento do consumidor; pesquisa qualitativa.

\begin{abstract}
In the Brazilian scenario, companies have becoming more interested in assuming a corporate social responsibility attitude. The understanding of consumer behavior, including what he or she thinks about this subject and what kind of influence it has over his or her decisions, is very important for strategic marketing decisions. The objective of this exploratory study is to increase the level of understanding about Brazilian consumers' reactions to corporate social responsibility attitude. A qualitative research was accomplished, and the chosen method was semi-structured interviews, in order allow us to have a thorough discussion on the subject with each consumer interviewed. The results suggest that consumers have a limited view about corporate social responsibility, selecting one or two aspects when trying to define the term. Mentioned aspects refer mostly to the solution of the country's basic problems, such as education and public health, and to firm's legal obligations, such as telling the truth to the public. The results about the influence of social responsibility on buying decisions show a dominance of negative information about the companies' attitude.
\end{abstract}

Key words: social responsibility; consumer behavior; qualitative research. 


\section{INTRODUÇÃO}

Há algumas décadas o tema responsabilidade social corporativa vem sendo alvo de inúmeros debates no meio acadêmico e empresarial. Mais recentemente, observa-se uma transformação no próprio conceito: de uma concepção antes baseada na caridade e no altruísmo, para uma associação entre responsabilidade social e estratégia empresarial (Smith, 1994). Em outras palavras, atuar como organização transformadora da sociedade passou a ser considerado pelas empresas como importante fonte de vantagem competitiva.

A busca por uma atitude de responsabilidade social corporativa, intensificada a partir da década de noventa, fez surgir um campo de estudo amplo dentro da administração e do marketing. Estudos nesta área partem do interesse em se entender como a percepção dos consumidores a respeito das empresas e de suas ofertas é formada e influenciada. A avaliação do consumidor em relação à postura de responsabilidade social de uma organização se insere no processo de decisão de compra, mas não há consenso a respeito da importância e do impacto desta informação nas escolhas dos consumidores. Apesar da relevância deste assunto ser crescente, segundo Litz (1996) existe um hiato significativo em relação ao estudo dos resultados gerados pelo desempenho de responsabilidade social das empresas. Outros autores também consideram que pouca ênfase tem sido dada até agora a estudos dos efeitos, no comportamento dos consumidores, da adoção deste tipo de postura por parte das organizações (Sen \& Bhattacharya, 2001).

O objetivo deste estudo é ampliar o nível de conhecimento das reações do consumidor brasileiro à postura de responsabilidade social das empresas. A primeira etapa incluiu uma revisão da literatura sobre o assunto, a fim de se construir um instrumental conceitual que formou a base para a pesquisa de campo. Esta teve caráter exploratório, seguindo uma metodologia qualitativa com uso de entrevistas semi-estruturadas, e buscou responder às seguintes questões: Qual a concepção do consumidor a respeito do tema responsabilidade social corporativa? Que aspectos estão envolvidos nesta concepção? De que forma a percepção de que a empresa é socialmente responsável influencia suas decisões de compra?

\section{Referencial Teórico: Responsabilidade Social Corporativa}

Uma série de mudanças quanto ao papel e ao nível de interferência do Estado na economia e na sociedade vem acontecendo no cenário mundial. Este fato, 
juntamente com o incremento na riqueza gerada pelas empresas privadas, vem gerando inúmeras discussões a respeito do papel das organizações privadas em questões de interesse público, apontando a importância de se atuar de forma socialmente responsável. Para Makower (1994), esta atuação deve derivar de uma postura mais filosófica do que pragmática, permeando objetivos, missão e políticas da empresa.

No entanto, se parece óbvio que as empresas deveriam fazê-lo, não há igual consenso quanto àquilo que de fato constitui uma postura de responsabilidade social corporativa. O histórico de definições para este tema caracteriza-se por certa imprecisão. Bower (1957) definiu responsabilidade social como as obrigações dos administradores de empresas de adotar orientações, tomar decisões e seguir linhas de ação que sejam compatíveis com os fins e valores de uma sociedade. Persiste, contudo, a dificuldade em se definir quais seriam os fins e valores adequados a cada sociedade e, por conseguinte, quais as linhas de ação a serem empreendidas.

Há dois enfoques principais acerca da responsabilidade social. A visão econômica clássica, amplamente difundida por Friedman (como citado em Ashley et al., 2003), postula que a empresa socialmente responsável é aquela que busca sempre responder às expectativas de seus próprios acionistas, maximizando o lucro. Este autor, Prêmio Nobel de Economia, questiona a existência da responsabilidade social corporativa, argumentando que, numa sociedade democrática, o Governo é o único veículo legítimo para tratar de questões sociais. As empresas não deveriam fazê-lo, pois estariam se distanciando de sua expertise.

Por outro lado, a visão socioeconômica defende o papel da organização na promoção do bem-estar social, com objetivos mais amplos do que a obtenção de lucros corporativos e geração de empregos, sem contudo ignorá-los. Alguns de seus princípios são: foco nos lucros de longo prazo para o negócio; obtenção de melhor imagem junto à sociedade e menor regulamentação governamental para o negócio; incorporação de maiores obrigações sociais para o negócio; promoção de melhor ambiente para todos. De acordo com esta abordagem, a empresa estará cumprindo sua responsabilidade social na medida em que proporcionar uma melhora nas condições de vida da sociedade.

Observando estas duas visões de forma integrada, pode-se observar que os adeptos de ambas as correntes consideram que para as empresas, na prática, a busca de um resultado positivo é uma questão de sobrevivência. É a sobrevivência da empresa que garante o atendimento dos interesses de seus acionistas e empregados, sendo condição necessária para pensar na realização de investimentos em atividades que favoreçam os demais stakeholders, de forma mais ampla. Mas é importante ressaltar que beneficiar os demais stakeholders 
não inclui somente ações que envolvam gastos extras, tais como doações a causas filantrópicas, por exemplo. Pagar os impostos devidos, por exemplo, bem como divulgar seu produto sem utilização de propaganda enganosa são, igualmente, atitudes que beneficiam a sociedade como um todo. Segundo Carrigan e Attalla (2001), as empresas enfrentam, muitas vezes, dificuldades para definir e praticar ações de responsabilidade social, e uma das razões para isto pode estar na dificuldade em decidir que interesse deve priorizar, e quem deve tomar a decisão final se houver conflito de interesses dos stakeholders. Porém, pelo menos segundo a visão socioeconômica, independentemente do grupo de stakeholders priorizado, a empresa não deve perder de vista a obediência a valores que contribuam para promoção do bem-estar social.

Ashley et al. (2003) consideram que a responsabilidade social engloba toda e qualquer ação da empresa que possa contribuir para a melhoria da qualidade de vida da sociedade. Segundo estes autores:

Responsabilidade social pode ser definida como o compromisso que uma organização deve ter para com a sociedade, expresso por meio de atos e atitudes que a afetem positivamente de modo amplo, ou a alguma comunidade de modo específico, agindo proativamente e coerentemente no que tange a seu papel específico na sociedade e a sua prestação de contas para com ela (p. 6-7).

Davis (como citado em Guimarães, 1984) argumenta que a responsabilidade social da empresa deriva justamente de seu grande poder social. Este autor aponta a importância do papel das empresas na sociedade, considerando que as decisões empresariais têm amplas consequiências sociais e que, portanto, não podem ser tomadas unicamente motivadas por fatores econômicos. Este autor admite que estas decisões e a implementação das ações delas derivadas poderão gerar custos, que poderão ser assumidos pelos próprios consumidores. Sendo assim, os gastos com a implementação de práticas de responsabilidade social corporativa poderão ser adicionados ao preço final dos produtos ou serviços vendidos por estas corporações. No entanto há carência de pesquisas que mostrem até que ponto os consumidores estão dispostos a assumir estes custos, e os resultados existentes são conflitantes. Alguns estudos mostraram que os consumidores estariam dispostos a pagar mais por produtos de empresas socialmente responsáveis (Creyer \& Ross, 1997; Peixoto, 2004), enquanto outros estudos mostraram que a responsabilidade social corporativa não exerce papel importante na decisão de compra e que, portanto, os consumidores não estariam dispostos a pagar a mais por isto (Carrigan \& Attalla, 2001; Mohr, Webb, \& Harris, 2001).

Alguns autores buscaram definir o conceito de responsabilidade social enfatizando as ações dele derivadas e respectivos beneficiários. Para Srour (1998), por exemplo, uma empresa socialmente responsável mantém parceria efetiva com clientes e 
fornecedores, gerando produtos de qualidade e assegurando durabilidade, confiabilidade e preços competitivos. Segundo o autor, as organizações devem empreender ações que contribuam para o desenvolvimento da comunidade, via projetos que aumentem o seu bem-estar, além de investimentos em pesquisa tecnológica para inovar processos e produtos, visando a melhor satisfazer seus clientes, além de preocupar-se ainda com a conservação do meio ambiente, através de intervenções não predatórias e de medidas que evitem consequiências externas negativas da atividade da empresa. Ademais, as empresas devem investir no desenvolvimento profissional dos trabalhadores e também em melhores condições de trabalho e em benefícios sociais. Na verdade, este autor identifica três beneficiários das ações da empresa, além de seus clientes: a comunidade, o meio ambiente e o trabalhador, seja ele empregado da própria empresa, terceirizado ou temporário.

Já para Oliveira (1984), os grupos beneficiários da responsabilidade social corporativa são cinco: os empregados; os consumidores; os credores e fornecedores; a comunidade; os acionistas, sócios ou proprietários. Assim como Carrigan e Attalla (2001), este autor assume que há divergência entre o interesse dos acionistas, sócios ou proprietários que visam à maximização do lucro, e o interesse dos demais grupos, o que gera um paradoxo para a empresa que tem a intenção de atender às expectativas de todos os seus stakeholders.

Complementando esta idéia, Melo Neto e Froes (2001) acreditam que as ações socialmente responsáveis da empresa aumentam a produtividade no trabalho, criam maior motivação, auto-estima e orgulho entre os funcionários. Estes autores argumentam que ações que gerem impacto positivo, tanto no ambiente interno quanto no ambiente externo da empresa, aprimoram a atmosfera de trabalho e determinam a melhoria significativa da qualidade de vida dos empregados.

Oliveira (1984) amplia o debate sobre o tema, propondo visões diversas sobre a forma de atuação das empresas na sociedade. Segundo ele, a responsabilidade social corporativa pode ser vista de diferentes formas: como comportamento empresarial pautado por uma orientação ética, como ações filantrópicas, ou, ainda, como responsabilidade legal ou obrigação social que a empresa deve ter.

Para Ferrell, Fraedrich e Ferrell (2000), a empresa socialmente responsável é aquela que, na busca por maximizar os efeitos positivos sobre a sociedade e minimizar os negativos, considera dimensões legais, econômicas, filantrópicas e éticas. Unindo o enfoque clássico e o socioeconômico, estes autores destacam que a responsabilidade social se desdobra nestas quatro dimensões.

A dimensão legal diz respeito ao cumprimento das leis e regulamentos estabelecidos pelo governo para garantir padrões mínimos de conduta responsável por parte das empresas. 
No que tange à dimensão ética, as empresas deveriam perseguir um comportamento considerado íntegro, certo e justo pela sociedade, além do que é exigido por lei. Isto inclui a percepção, por parte das organizações, de valores e expectativas de seus stakeholders. Assim, a esfera ética inclui a adoção de princípios e valores que não podem ser postos em risco, nem mesmo em nome do cumprimento de metas internas da empresa.

A dimensão econômica refere-se à busca de lucro e retorno aos investidores por parte das empresas. A responsabilidade de natureza econômica leva também à geração de empregos para sustentar o crescimento da organização.

Ao destinar recursos humanos e financeiros para melhorar a qualidade de vida da sociedade em geral e, mais especificamente, das comunidades onde opera, a empresa cumpre com sua responsabilidade filantrópica. Preservação do meio ambiente, investimentos em educação e donativos para obras de caridade são algumas demandas sociais que a empresa pode atender.

De acordo com Ferrell et al. (2000), a adoção da responsabilidade social corporativa harmoniza-se com a percepção de que a empresa é responsável pelas consequiências sociais de suas ações. Isto funciona, na prática, como uma filosofia da organização, crença que deve guiar todas as suas ações e decisões, desde o princípio de suas operações. Neste contexto, zelar pela lucratividade e sobrevivência da empresa faz parte de sua responsabilidade social (dimensão econômica) e não há hierarquia de valores entre as já citadas dimensões da responsabilidade social. Estes autores defendem que, no contexto atual, uma empresa que pauta suas ações pela responsabilidade social corporativa em todas as suas dimensões tende a incrementar sua lucratividade e aumentar suas chances de sobrevivência de longo prazo.

Buscando obter evidências empíricas acerca desta afirmação, alguns autores procuraram mostrar os benefícios que o exercício da responsabilidade social traz para as empresas, tanto em relação à valorização da imagem institucional (File \& Prince, 1998) quanto no que diz respeito ao desenvolvimento de atitudes favoráveis dos consumidores em relação à empresa (Smith \& Alcorn, 1991).

O retorno financeiro para as empresas tem recebido atenção de diversos estudos. Uma parte deles se dedicou a avaliar os efeitos das ações de responsabilidade social e o desempenho financeiro das empresas. Alguns autores encontraram evidências de uma correlação entre estas duas variáveis (McGuire, Sungren, \& Schneewels, 1988; Pava \& Krausz, 1996), enquanto outros concluíram pela ausência desta correlação (Aupperle, Carroll, \& Hatfield, 1985).

Estudos mais recentes vêm focando atenção nos efeitos da responsabilidade social corporativa na atitude de funcionários e consumidores (para uma revisão destes 
estudos ver Sen \& Bhattacharya, 2001). Dentre estes, merece destaque uma pesquisa conduzida por Brown e Dacin (1997), que trata mais especificamente da correlação positiva entre preferência dos consumidores pelos produtos das empresas e a responsabilidade social desta, mostrando que esta correlação passa pelo fato de os consumidores fazerem uma avaliação geral da empresa em si, quando envolvidos no processo de decisão de compra. Os autores argumentam que o histórico de ações de responsabilidade social das empresas não proporciona propriamente informações sobre os atributos de qualidade de seus produtos, mas cria um contexto geral favorável dentro do qual o consumidor constrói sua avaliação.

Muitos autores consideram que os consumidores do novo milênio são mais bem informados e educados sobre seus direitos e sobre a responsabilidade das empresas para com a sociedade (Titus \& Bradford, 1996). Mas Carrigan e Attalla (2001) apontam que há resultados conflitantes oriundos de pesquisas a respeito dos efeitos da percepção da responsabilidade social corporativa no comportamento do consumidor. Estes autores defendem a idéia de que uma das possíveis explicações para estes resultados não conclusivos é que os consumidores, mesmo sabendo mais sobre seus direitos, são relativamente mal informados sobre a postura das empresas e suas práticas e, muitas vezes, não são capazes de classificar uma empresa como socialmente responsável.

Um estudo de Boulstridge e Carrigan (2000) corrobora esta afirmação, mostrando que a maior parte dos consumidores carece de informações sobre o comportamento socialmente responsável das empresas. Os resultados deste estudo mostraram que os critérios mais importantes para decisão de compra são preço, valor, qualidade e familiaridade com a marca. Inúmeros autores buscaram e buscam construir o conceito de responsabilidade social corporativa e, sobretudo, encontrar uma definição que possa ser de fato praticada pelas empresas, gerando retorno em vários níveis. No entanto torna-se importante esclarecer uma confusão conceitual que existe na literatura sobre o assunto, confusão esta que se dá entre o conceito de responsabilidade social corporativa e a realização de projetos sociais isolados. Ser socialmente responsável significa ter a visão empresarial de que tudo o que é feito pela organização gera uma variedade de impactos diretos e indiretos dentro e fora dela, atingindo desde os consumidores e empregados até a comunidade e o meio ambiente (Correa \& Ferreira, 2000). Neste sentido, seus objetivos e políticas devem ser elaborados levando-se em conta estes impactos. Pode-se concluir, portanto, que a responsabilidade social requer algo além do atendimento a leis e padrões éticos de conduta: requer participação efetiva e transformadora nas questões da sociedade.

É inegável que muitas empresas já refletem sobre esta forma de ver as coisas. Questões sobre o impacto desta visão no comportamento dos consumidores, no 
entanto, permanecem. Creyer e Ross (1997) reforçam a importância de estudos nesta área, argumentando que, embora a adoção de uma atitude socialmente responsável se venha tornando cada vez mais importante para as empresas, é preciso questionar se os consumidores realmente levam isso em conta na sua tomada de decisão de compra. Segundo Murray e Vogel (1997), a relutância de algumas empresas em desenvolver programas de responsabilidade social corporativa pode ser atribuída ao fato de estas atividades representarem muitas vezes algo custoso e sem retorno óbvio ou de fácil mensuração para a empresa. É importante ressaltar que as empresas, sobretudo em mercados competitivos, buscam essencialmente a sua sobrevivência. Neste sentido, a realidade do mundo dos negócios exige que a empresa esteja focada na geração de lucros e no retorno a seus acionistas, até para que possa existir e gerar empregos, impostos e mesmo investir em programas sociais. Mas, como se viu, a exigência de lucro e sobrevivência pode conviver harmoniosamente com a responsabilidade social, se entendida de forma mais ampla, como filosofia da empresa.

No contexto brasileiro, o comprometimento das empresas com uma postura de responsabilidade social é relativamente recente, sendo este um tema ainda em desenvolvimento (Ashley et al., 2003). Algumas pesquisas mostram indícios de que se trata de assunto que vem gerando interesse não só no ambiente acadêmico, mas também no mundo corporativo. Uma pesquisa feita pelo Instituto de Pesquisas Econômicas Aplicadas (Ipea), em 1998, concluiu que 67\% das empresas da região Sudeste já promoveram atividades sociais voltadas para a comunidade. Outra pesquisa, realizada em 2004 pelo Instituto Ethos de Empresas e Responsabilidade Social, analisou as percepções e tendências do consumidor brasileiro em relação aos aspectos relevantes envolvidos na atuação social de empresas e a influência dessa visão nas relações de consumo. Segundo esta pesquisa, o consumidor brasileiro vem valorizando cada vez mais a atuação socialmente responsável das empresas. Perguntados sobre qual o papel das empresas, os participantes desta pesquisa escolheram a opção que descrevia a atitude empresarial de contribuição para a melhoria da sociedade, indo além do simples cumprimento das leis. Vale ressaltar, com relação à mesma pesquisa feita em anos anteriores, que a escolha por esta opção cresceu nove pontos percentuais do ano de 2000 ao ano de 2004. Não há, no entanto, respostas conclusivas a respeito da percepção das pessoas acerca deste conceito e qual o impacto de uma postura de responsabilidade social corporativa na construção da imagem da empresa e nas decisões de compra. Ashley et al. (2003) afirmam:

Há, entretanto, uma questão que deve ser colocada: o que se entende por responsabilidade social no Brasil? Esse questionamento é importante para esclarecer o que está presente no discurso, possibilitando extrair perspectivas quanto aos trabalhos que serão efetivamente realizados (p.75). 
Este estudo busca contribuir para este questionamento no contexto brasileiro, explorando a percepção dos consumidores sobre o tema.

\section{Metodologia de Pesquisa}

A escolha da metodologia deste estudo pautou-se pelo interesse em ampliar o entendimento do conceito de responsabilidade social corporativa, do ponto de vista do consumidor brasileiro. Por se tratar de tema ainda pouco explorado, sobretudo no universo brasileiro, a metodologia qualitativa, com uso de entrevistas semi-estruturadas, vem-se adequando aos objetivos pretendidos. Segundo Goldman e McDonald (1987), o uso de métodos qualitativos comofocus groups e entrevistas é bastante útil em pesquisas sobre temas ainda pouco estudados, como é o caso da responsabilidade social corporativa no contexto brasileiro.

Para coleta dos dados foram conduzidas dez entrevistas com roteiro semiestruturado (vide Anexo 1). A composição do grupo pautou-se pela busca de um padrão social comum, bem como de faixa etária também semelhante. Estes cuidados foram tomados para que se pudesse encontrar no grupo de entrevistados um mínimo de valores comuns. Foram entrevistados 5 homens e 5 mulheres, de 30 a 38 anos, com nível superior completo. A descrição dos participantes encontrase no Anexo 2.

Para guiar o tratamento do material coletado nas entrevistas, foi utilizada a análise hermenêutica. Para Minayo (2004), a hermenêutica é a busca de compreensão de sentido que se dá na comunicação entre as pessoas, cujo núcleo central é a linguagem. Por meio da interpretação da linguagem, pode-se compreender representações e contextos culturais relacionados à localização histórica e social do emissor da mensagem. Cumpre ressaltar que qualquer interpretação produzida segundo a proposta se hermenêutica se liga inexoravelmente ao viés histórico e social do analista.

Assim, na fase inicial da entrevista, procurou-se obter informações acerca do grupo socioeconômico, idade, nível educacional e formação de cada entrevistado, para que se pudesse contextualizar seu discurso. De acordo com Thompson (1997), a interpretação hermenêutica de dados textuais se dá através de uma série de interações da parte e do todo, valorizando as próprias palavras dos entrevistados. Segundo o autor, este processo interativo envolve dois estágios distintos. O primeiro é um ciclo intratexto, em que um texto é lido em sua totalidade para ganhar sentido de todo. Leituras adicionais são empreendidas para desenvolver uma compreensão dos significados presentes no texto. $\mathrm{O}$ 
segundo movimento é da parte para o todo, intertextual, em que se procuram padrões e diferenças entre as entrevistas. Também há movimentos interativos entre os ciclos intra e intertextuais.

Algumas limitações da metodologia escolhida devem ser apontadas. Primeiramente, há que se considerar que este é um estudo sobre o comportamento humano, onde a entrevista busca trazer à tona questões relativas a percepções e à tomada de decisão de compra. O método de entrevistas abre a possibilidade de as pessoas buscarem dar respostas que estejam de acordo com normas e convenções sociais estabelecidas, eximindo-se de dar verdadeiramente suas opiniões sobre os assuntos questionados. Desta forma, os resultados dependerão fundamentalmente da sinceridade dos respondentes para expressar suas opiniões. Uma forma de se evitar este viés é motivar os indivíduos a dar as informações mais genuínas sobre suas próprias percepções, ressaltando a importância desta atitude para a legitimidade da pesquisa e pontuando que o estudo não tem a intenção de julgamento de valor das opiniões dos sujeitos pesquisados.

Outra limitação inerente a este método é que ele não é capaz de contemplar todas as variáveis envolvidas no complexo processo de tomada de decisão de compra. Segundo Simonson, Carmon, Dhar, Drolet, e Nowlis (2001), as pesquisas no campo da tomada de decisão do consumidor podem envolver aspectos frios, ligados à atenção, percepção, aquisição de informação, aprendizado etc.; e aspectos quentes, ligados às emoções. Apesar de reconhecer a importância destes últimos, este estudo está focado fundamentalmente na percepção do consumidor envolvida no processo de busca de informação para tomada de decisão de compra.

Por fim, há o fato de a pesquisa ter sido realizada com um grupo de dez pessoas, moradoras da cidade do Rio de Janeiro. Trata-se de um número reduzido de participantes, o que faz com que os resultados aqui apresentados não possam ser considerados como base única para uma avaliação do que pensa o consumidor brasileiro. Embora a pesquisa qualitativa não busque a generalização estatística de seus resultados, vale ressaltar que as informações geradas pelos participantes devem servir para um início de reflexão sobre o tema responsabilidade social corporativa no contexto do consumidor brasileiro. Não são, portanto, conclusivas, mas embrionárias de estudos futuros do tema, e isto deve ser levado em conta ao se analisar os resultados encontrados. Ainda assim, justifica-se a escolha da metodologia, pelo fato de gerar uma riqueza de conteúdo que poderá suscitar diversas indagações para pesquisas futuras. 


\section{AnÁlise dos Resultados}

As entrevistas buscaram explorar três aspectos da postura de responsabilidade social corporativa (doravante denominada RSC) no Brasil: 1. Como as pessoas definem RSC, incluindo quais os aspectos envolvidos nesta definição; 2. Como percebem a existência de informações acessíveis sobre o assunto, incluindo lembranças de exemplos de empresas com esta postura que atuem em território brasileiro; 3. Como a postura das empresas com relação a este tema influencia seu comportamento como consumidor.

A primeira fase da análise dos resultados buscou encontrar semelhanças entre os discursos das entrevistas, observando padrões nas respostas dadas. O primeiro ponto que merece destaque é que a unanimidade dos entrevistados considera que o conceito de RSC é bastante recente no contexto brasileiro, como de fato afirmam diversos autores nacionais (ver, por exemplo, Ashley et al., 2003). Os participantes demonstraram dificuldade em sugerir definições para o conceito, e muitos admitiram textualmente que o assunto é novo para eles, considerando, por exemplo, que a RSC 'parece ser uma nova onda de consciência das empresas no Brasil'. Embora o assunto tenha sido objeto de reportagens em revistas de negócios, prêmios, seminários, além de algumas pesquisas acadêmicas (como por exemplo, Correa \& Ferreira, 2000), permanece ainda para o consumidor a idéia de que ele é recente, pouco conhecido, e de que somente há pouco tempo as empresas têm refletido mais sobre o tema.

Trata-se de observação importante, tanto para acadêmicos quanto para gestores de empresas. Para os primeiros, porque estudos que assumam familiaridade com os consumidores como tema podem estar sujeitos a algum viés de pesquisa. Devese levar em conta que, num grupo de pessoas com alto nível de instrução e com acesso privilegiado a informações, a maior parte demonstrou uma não-familiaridade com o tema. Para os gestores de empresas, torna-se importante entender o nível de conhecimento de seu público com relação a este tipo de postura empresarial, sobretudo para que, numa estratégia de comunicação com o mercado, isto possa ser levado em conta. As empresas interessadas em informar seus clientes a respeito deste tema devem buscar os meios adequados para fazê-lo, visto que, para os entrevistados, é preciso que a informação chegue facilmente até eles, e não que eles tenham de empreender esforços para buscá-las.

O fato de o tema ser novo para as pessoas pode ser entendido como uma das razões pelas quais a forma como os respondentes definiram responsabilidade social se apresente tão fragmentada. A maioria escolheu um ou dois aspectos que considera importante na atuação das empresas, e 
colocou-o como definição do termo. Os principais aspectos mencionados pelos entrevistados foram: educação, saúde, meio ambiente, desnutrição, mortalidade infantil, qualidade de produtos e serviços, honestidade nas informações que a empresa fornece ao mercado, relação com os funcionários, reciclagem. É interessante notar que cada entrevistado citou um, dois ou três aspectos diferentes desta lista, o que denota falta de consenso do tipo de impacto que a empresa socialmente responsável deveria gerar para a sociedade. Nas definições apresentadas fica claro o papel conferido às empresas de atuar em soluções dos problemas mais básicos do país. Frases como 'as empresas socialmente responsáveis devem suprir a carência em educação que o país tem', exemplificam este aspecto.

Partindo de uma análise das diferenças encontradas entre os discursos dos entrevistados, temos que apenas um demonstrou ter visão mais ampla do tema, relacionando o conceito de responsabilidade social não a aspectos específicos, mas à importância de se gerar um retorno para a sociedade em função daquilo que a empresa recebe. A contrapartida da empresa não foi lembrada por praticamente nenhum entrevistado. Apenas um assinalou em que aspectos a empresa socialmente responsável poderia obter ganhos junto à sociedade, observando que 'as empresas têm de pensar no retorno e este se dá sob a forma de melhoria da imagem da marca'.

Em algumas entrevistas pôde-se ver claramente uma relação entre a RSC e a transmissão de informações verdadeiras ao consumidor. Isto sugere um sintoma de que os entrevistados ainda não têm a real dimensão dos seus direitos como consumidores, considerando como socialmente responsável a empresa que simplesmente respeita estes direitos, assegurados em lei. A citação feita por um dos entrevistados de que RSC 'tem a ver com honestidade, ou seja, se as informações dadas sobre seu produto são verdadeiras', ilustra bem este aspecto e foi repetida pela maioria dos entrevistados, ainda que com diferentes palavras. Neste sentido, as empresas que cumprem a lei, cuidando da veracidade das informações fornecidas aos consumidores, foram valorizadas e receberam menções respeitosas dos consumidores entrevistados.

Um aspecto interessante no que se refere à classificação do que é RSC diz respeito ao dilema longo prazo versus curto prazo. Observou-se nas entrevistas uma tendência a se relacionar uma postura de RSC com projetos de longo prazo, rechaçando ações que visem apenas resultados de curto prazo. Estas últimas foram citadas de forma pejorativa pelos entrevistados, fazendo alusão até mesmo ao fato de que a empresa busca posicionar-se como socialmente responsável pelo fato de este ser um conceito novo, que está 'na moda', como mostram as afirmações a seguir: 
'As empresas devem pensar a RSC como projeto, não como ações isoladas'.

'O assunto agora está entrando mais na moda; vemos na mídia, em palestras etc'.

Pelos depoimentos analisados, pôde-se constatar que as empresas parecem contribuir para que este tema não seja familiar às pessoas. Novamente a análise das semelhanças entre os discursos dos entrevistados mostrou que há certa unanimidade na constatação de que as empresas não se preocupam em divulgar suas práticas de RSC. Os entrevistados consideram que é o próprio consumidor que acaba tendo que se informar sobre o assunto - 'aquele que se interessa tem de buscar essas informações' - e que as empresas não sabem como divulgar adequadamente sua postura de RS.

Explorando mais profundamente essa questão nas entrevistas, pôde-se constatar que a escassez de informação sobre RSC parece ter como consequiência uma desconfiança com relação ao que as empresas efetivamente fazem nesta área. Alguns entrevistados mostraram em suas declarações uma relação direta entre a falta de informação e escassez de ações socialmente responsáveis das empresas, como por exemplo:

'[As empresas] tentam supervalorizar o pouco que fazem para valorizar a imagem delas. Mas fazem muito pouco'.

'Acho que se é pouco divulgado é porque as empresas fazem pouco'.

Entretanto, além das declarações textuais acima mencionadas, outro resultado das entrevistas aponta a falta de informações sobre RSC no Brasil. Todos os entrevistados foram confrontados com uma pergunta direta sobre se se lembravam de alguma empresa, de qualquer setor da economia, que eles considerassem como socialmente responsável. No total foram lembrados apenas quatro exemplos, sendo dois deles de empresas estrangeiras com atuação no Brasil: MacDonald's ('Mac Dia Feliz'), Nestlé, Petrobras, Bradesco ('Fundação Bradesco').

Além das definições de RSC e da percepção sobre a existência ou não de informações disponíveis a respeito do tema, o terceiro aspecto analisado nos depoimentos colhidos é o possível impacto que uma postura de RSC pode ter no comportamento dos entrevistados como consumidores. Na medida em que as entrevistas foram realizadas a partir de roteiro semi-estruturado, os participantes foram deixados livres para comentar, de forma espontânea, a RSC em seus comportamentos. Porém nenhum dos entrevistados mencionou espontaneamente este aspecto, e uma pergunta induzindo considerações a esse respeito foi feita. Uma diferença significativa pôde ser observada entre as respostas dos participantes, neste momento da entrevista e quando buscavam definir RSC. Como se viu, para chegar a uma definição de RSC, todos os entrevistados mencionaram 
impactos positivos que a empresa pode gerar para sociedade, tais como melhorias na educação da população, preservação do meio ambiente, respeito a seus funcionários. No entanto, quando levados a responder sobre o efeito de uma postura de RSC em seu comportamento como consumidores, a maioria privilegiou aspectos negativos, isto é, como age uma empresa que não é socialmente responsável. As declarações a seguir ilustram esta constatação.

'O que influencia é saber de coisas erradas que as empresas fazem, isto me influencia a não comprar. Por exemplo, quero trocar de carro e não vou comprar um carro americano por conta da postura do governo dos EUA perante o mundo'.

'Não compraria produtos de empresas que praticam atividades econômicas não condizentes com a saúde social do Brasil'.

'Não compro produtos que agridam o meio ambiente, produtos testados em animais também não'.

Efeitos negativos das práticas das empresas - ou até de seu país de origem parecem causar mais impacto no comportamento dos consumidores entrevistados do que práticas vistas como positivas. Talvez pelo fato de as empresas atuantes no Brasil não terem desenvolvido ainda uma prática continuada de RSC e tenham dificuldade em fazer chegar aos consumidores este tipo de informação, os aspectos negativos são mais lembrados pelos consumidores e, portanto, parecem influenciar mais sua decisão de compra.

A análise das entrevistas mostra que as quatro dimensões da RSC sugeridas por Ferrell et al. (2000) estão presentes nas respostas obtidas. As mais citadas são a filantrópica e a ética, como se ilustra nos depoimentos anteriormente transcritos. A dimensão econômica é tida como a mais importante apenas por um dos entrevistados - economista - que considera socialmente responsáveis as empresas que não empreendem práticas mafiosas de controle de preços.

A dimensão dominante na fala dos entrevistados foi a filantrópica. Entretanto é interessante notar que a RSC foi associada com freqüência à filantropia, mas raramente foi associada somente a isto. A idéia de que a empresa é responsável pelas conseqüências de seus atos sobre a sociedade apareceu em grande parte das respostas, mesmo que de maneira difusa e, em alguns casos, especificando apenas alguns destes impactos.

Com relação aos beneficiários da postura de RSC das empresas, os que concentraram maior atenção dos entrevistados foram clientes, funcionários e comunidade em geral. Investidores e acionistas, personagens principais da visão clássica de RSC, praticamente não apareceram nos depoimentos analisados. Isto pode dever-se ao fato de que os entrevistados, por sua faixa etária e momento de 
vida, pertençam exatamente às três primeiras categorias - clientes e funcionários de empresas, bem como membros da comunidade em geral - e não das duas últimas - investidores e acionistas de empresas. De qualquer forma, este parece ser um indício de que os entrevistados enxergam além da visão clássica de RSC difundida por Friedman (como citado em Ashley et al., 2003).

A análise intratexto do discurso dos entrevistados sobre responsabilidade social harmoniza-se com a visão socioeconômica do termo. Diante do agravamento de uma vasta gama de problemas econômicos, sociais e ambientais em escala mundial, e da incapacidade dos governos para solucioná-los, parece haver uma exigência cada vez maior em relação ao papel das empresas na promoção do bem-estar social. Com isso o enfoque socioeconômico da responsabilidade social se fortalece, suplantando a visão clássica. Esta constatação parece estar em consonância com o desenvolvimento de organizações do chamado Terceiro Setor no contexto brasileiro, com a aplicação de capital privado, visando a ações transformadoras de interesse público. Desta forma, já se vê hoje um movimento da sociedade brasileira de não esperar pelo poder público para promover mudanças no cenário socioeconômico. A análise das entrevistas realizadas sugere que estes consumidores estão alinhados com a expectativa de ver o mundo empresarial, de alguma forma, mais atuante em questões importantes para a sociedade brasileira.

\section{Considerações Finais}

O presente estudo visou explorar o conceito de responsabilidade social corporativa junto a um grupo de consumidores de classe média brasileira. $\mathrm{O}$ caráter exploratório da pesquisa possibilitou uma análise inicial das idéias relacionadas ao conceito, bem como da percepção dos entrevistados a respeito da disponibilidade de informações e do efeito destas sobre sua intenção de compra. $\mathrm{O}$ método de entrevistas individuais visou ao aprofundamento do discurso dos entrevistados, possibilitando a análise de semelhanças e diferenças entre eles.

Os resultados sugerem que, para alguns, o conceito de RSC parece estar ligado a obrigações básicas da empresam, tais como fornecer informações sobre os seus produtos e falar a verdade para o consumidor. Para outros este conceito relaciona-se com a resolução de problemas socioeconômicos do país. Estes resultados devem ser considerados à luz da realidade brasileira. A conscientização dos direitos do consumidor é conquista relativamente recente no Brasil, fazendo com que a empresa que atenda aos direitos básicos dos clientes já seja considerada como socialmente responsável. Adicione-se a isso o fato de este ser ainda um 
país com fortes desigualdades sociais, o que gera nas pessoas uma expectativa de que as empresas devem oferecer uma contrapartida social do lucro que recebem.

Os consumidores entrevistados demonstraram ter pouco acesso a informações sobre RSC. Muito embora haja atualmente no contexto brasileiro uma série de publicações, prêmios e seminários sobre o tema, parece ainda haver grande área de oportunidade para as empresas interagirem com os consumidores a respeito dele. Esta interação pode gerar não apenas maior conhecimento para as pessoas sobre as atitudes e ações empreendidas pelas empresas, mas também um aprendizado para estas acerca do que os consumidores valorizam no campo da RSC. É interessante ressaltar o valor que a informação de aspectos negativos pode ter na intenção de compra do consumidor, como visto nos depoimentos colhidos. Este fato não pode deixar de ser considerado pelas empresas na gestão de sua comunicação com o mercado e, sobretudo, na tomada de decisão a respeito de ações que poderão gerar impactos percebidos como negativos pela sociedade.

Embora este efeito da informação dos aspectos negativos das ações das empresas tenha sido ressaltado, os resultados encontrados nas entrevistas não permitem a afirmação de que uma empresa socialmente responsável verá um impacto direto em suas vendas. Carrigan e Attalla (2001) apontam uma reflexão intrigante no que se refere ao estudo do efeito da postura de RSC em sua dimensão ética sobre o comportamento do consumidor: "Moralmente e eticamente é desejável que o marketing seja mais ético em suas atividades; porém pode ser que isto não necessariamente seja comercialmente benéfico (p. 574)". De certo ainda há campo aberto para estudos nesta área, sobretudo no contexto brasileiro. Nossa pesquisa buscou iniciar uma discussão a esse respeito, e seus resultados deverão ser complementados por estudos futuros, que deverão tratar do tema de diversas formas.

Investigações qualitativas junto a outros grupos de consumidores poderão encorpar o conhecimento a respeito de como o conceito de RSC está posicionado na mente das pessoas, seja através de entrevistas, grupos de foco ou técnicas de observação. Estudos que utilizam métodos quantitativos poderão ser combinados com estes primeiros, numa tentativa de relacionar a percepção de RSC com uma efetiva intenção de compra do consumidor brasileiro. Investigar percepções e intenções de comportamento não são tarefas simples, mas representa desafio importante para o pesquisador interessado em entender mais amplamente o comportamento do consumidor. No campo da responsabilidade social, informações que ajudem a esclarecer a interação de empresas e consumidores muito podem contribuir para maior atenção de todos os envolvidos com o tema. Estudos focados nos possíveis retornos para as empresas - em termos de construção de imagem, influência positiva na atitude e no comportamento dos consumidores, aumento de 
lucratividade etc. - podem incentivar a formação de uma atitude de RSC por parte das organizações. Por outro lado, pode-se supor que consumidores mais bem informados do tema se tornem mais sensíveis a esta atitude por parte das empresas, e portanto mais atuantes. A divulgação de estudos nesta área pode ajudar a construir uma atitude favorável ao tema no contexto brasileiro, gerando ganhos para toda a sociedade.

\section{Artigo recebido em 25.10.2004. Aprovado em 05.06.2005.}

\section{Referências Bibliográficas}

Ashley, P.,

Queiroz,A.,

Cardoso, A.,

Souza, A.,

Teodósio, A., \&

Borinelle, B. et al. (2003).

Ética e responsabilidade social nos negócios. Rio de Janeiro: Editora Saraiva.

Aupperle, K. E.,

Carroll, A. B., \&

Hatfield, J. D. (1985).

An empirical examination of the relationship between corporate social responsibility and profitability. Academy of Management Journal, 28(2), 446-463.

Boulstridge, E., \&

Carrigan, M. (2000).

Do consumers really care about corporate responsibility? highlighting the attitude-behavior gap. Journal of Communication Management, 4(4), 355-368.

Bower, H. R. (1957).

Responsabilidades sociais dos homens de negócio. Rio de Janeiro: Editora Civilização Brasileira S.A.
Brown, T. J., \&

Dacin, P. A. (1997).

The company and the product: corporate associations and consumer product responses. Journal of Marketing, 61(1), 68-84.

Carrigan, M., \&

Attalla, A. (2001).

The myth of the ethical consumer do ethics matter in purchase behavior? Journal of Consumer Marketing, 18(7), 560-577.

Correa, S. C. H., \&

Ferreira, A. L. (2000).

Responsabilidade social: aspectos menos visíveis de um caso de sucesso. Anais do Encontro Nacional dos Programas de PósGraduação em Administração, Florianópolis, SC, 24.

Creyer, E. H., \&

Ross, W. T. (1997).

The influence of firm behavior on purchase intention: do consumer really care about business ethics? Journal of Consumer Marketing, 14(6), 421-433. 
Ferrell, O.C.,

Fraedrich, J., \&

Ferrell, L. (2000).

Business ethics: ethical decision making and cases (4th ed.). Boston: Houghton Mifflin.

File, K. M., \&

Prince, R.A. (1998).

Cause related marketing and corporate philanthropy in the privately held enterprise, Journal of Business Ethics, 17(14), 1529-1539.

Goldman, A. E., \&

McDonald, S. S. (1987).

The groups depth interview: principles and practice, PrenticeHall: New Jersey.

Guimarães, H. W. M. (1984).

Responsabilidade social da empresa: uma visão histórica de sua problemática. Revista de Administração de Empresas, 24(4), 211-219.

Litz, R. A. A. (1996).

A resource-based-view of the socially responsible firm: stakeholder interdependence, ethical awareness, and issue responsiveness as strategic assets. Journal of Business Ethics, 15(12), 1355-1363.

Makower, J. (1994).

Beyond the bottom line: putting social responsibility to work for your business and the world. New York: Simon \& Schuster.

McGuire, J. B.,

Sungren, A., \&

Schneewels, T. (1988).

Corporate social responsibility and firm financial performance. Academy of Management Journal, 31(4), 869882.

Melo Neto, F. P., \&

Froes, C. (2001).

Gestão da responsabilidade social corporativa: o caso brasileiro. Rio de Janeiro: Editora Qualitymark.

Minayo, M. C. S. (2004).

$O$ desafio do conhecimento pesquisa qualitativa em saúde. São Paulo: Hucitec.

Mohr, L. A.,

Webb, D. J., \&

Harris, K. E. (2001).

Do consumers expect companies to be socially responsible? The impact of corporate social responsibility on buying behavior. The Journal of Consumer Affairs, 35(1), 45-72.

Murray, K. B., \&

Vogel, C. M. (1997).

Using a hierarchy-of-effects approach to gauge the effectiveness of corporate social responsibility to generate goodwill toward the firm: financial versus nonfinancial Impacts. Journal of Business Research, 38(2), 141-159.

Oliveira, J. A. (1984).

Responsabilidade social em pequenas e médias empresas. Revista de Administração de Empresas, 24(4), 203-210.

Pava, M. L., \&

Krausz, J. (1996).

The association between corporate social-responsibility and financial performance: the paradox of social cost. Journal of Business Ethics, 15(3), 321-358. 
Peixoto, M. C. (2004).

Responsabilidade social e impacto no comportamento do consumidor: estudo de caso da indústria de refrigerantes. Dissertação de Mestrado, Pontifícia Universidade Católica, Rio de Janeiro, RJ, Brasil.

Sen, S., \&

Bhattacharya, C. B. (2001).

Does doing good always lead to doing better? Consumer reactions to corporate social responsibility. Journal of Marketing Research, 38(2), 225-243.

Smith, C. (1994).

The new corporate philanthropy. Harvard Business Review, 72(3), 105116.

Smith, S. M., \&

Alcorn, D. S. (1991).

Cause marketing: a new direction in the marketing of corporate responsibility, The Journal of Consumer Marketing, 8(3), 19-35.
Simonson, I.,

Carmon, Z.,

Dhar, R.,

Drolet, A., \&

Nowlis, S. M. (2001).

Consumer research: in search of identidy. Annual Review of Psychology, 52, 249-275.

Srour, R. H. (1998).

Poder, cultura e ética nas organizações. Rio de Janeiro: Editora Campus.

Thompson, C. J. (1997).

Interpreting consumers: a hermeneutical framework for deriving marketing insights from the texts of consumers' consumption stories. Journal of Marketing Research, 34(4), 438-455.

Titus, P. A., \&

Bradford, J. L. (1996)

Reflections on consumer sophistication and its impact on ethical cusiness practice. Journal of Consumer Affairs, 30(1), 170-195. 


\section{ANEXO 1}

\section{Roteiro Semi-Estruturado de Entrevista}

. Que entende por responsabilidade social nas empresas?

- Procure lembrar-se de empresas que atuam no Brasil que tenham uma postura de responsabilidade social, na sua opinião.

- Você busca informações sobre esta postura das empresas? De que forma você consegue, ou poderia conseguir, estas informações? Você acha que as empresas informam o consumidor sobre isto?

Estas informações influenciam de alguma forma as suas escolhas na hora de comprar algo? 


\section{ANEXO 2}

\section{Perfil dos ENTREVISTADOS}

\begin{tabular}{ll}
\hline \multicolumn{2}{c}{ ldade } \\
\hline 30 anos & 3 \\
32 anos & 2 \\
33 anos & 2 \\
36 anos & 2 \\
38 anos & 1 \\
\hline
\end{tabular}

\begin{tabular}{ll}
\hline \multicolumn{2}{c}{ Formação } \\
\hline Psicólogo & 2 \\
Economista & 4 \\
Administrador & 2 \\
Biólogo & 1 \\
Jornalista & 1 \\
\hline
\end{tabular}

\begin{tabular}{ll}
\hline \multicolumn{2}{c}{ ldade } \\
\hline 30 anos & 3 \\
32 anos & 2 \\
33 anos & 2 \\
36 anos & 2 \\
38 anos & 1 \\
\hline
\end{tabular}

